\title{
Comparison of the Efficacy of Septoplasty with Nonsurgical Management in Improving Nasal Obstruction in Patients with Deviated Nasal Septum - A Randomized Clinical Trial
}

\author{
Dharanya Gopalakrishnan Srinivasan ${ }^{10}$ Jyotirmay Hegde ${ }^{2(1)}$ Karthikeyan Ramasamy ${ }^{3}$ (1)

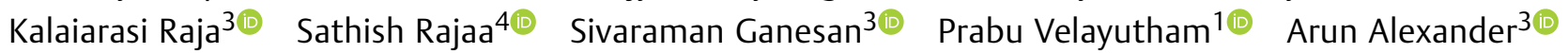 \\ Sunil Kumar Saxena ${ }^{30}$
}

${ }^{1}$ Department of Otorhinolaryngology, Shri Venkateshwaraa Medical College and Hospital, Puducherry, India

2 Department of Otorhinolaryngology, Columbia Asia Hospital, Whitefield, Bangalore, India

${ }^{3}$ Department of Otorhinolaryngology, Jawaharlal Institute of Postgraduate Medical Education and Research, Puducherry, India

${ }^{4}$ Department of Preventive and Social Medicine, JIPMER, Puducherry, India

\begin{abstract}
Address for correspondence Dharanya GS, MS, Department of Otorhinolaryngology, Shri Venkateshwaraa Medical College and Hospital, Puducherry, India (e-mail: natural.dharanyasrinivasan@gmail.com).
\end{abstract}

Int Arch Otorhinolaryngol 2022;26(2):e226-e232.

\author{
Abstract \\ Keywords \\ - visual analogue scale \\ - PNIF \\ - SNOT-22 \\ - NOSE score \\ - intranasal \\ corticosteroids \\ - topical \\ decongestants
}

Introduction In the current era, the major indication for septoplasty is nasal obstruction due to deviated nasal septum (DNS). Even though septoplasty is a commonly performed surgery, its effectiveness in relieving nasal obstruction in DNS has not been proven.

Objective The present study involved the measurement of both objective (nasal patency) and subjective (quality of life measures) outcome measures for the evaluation of the efficacy of septoplasty as compared with medical management.

Methods Patients with DNS presenting with nasal obstruction were included and randomized into a septoplasty group or into a nonsurgical management group, with 70 patients in each group. The improvement in nasal obstruction was assessed subjectively by the visual analogue scale (VAS), and the sino-nasal outcome test-22 (SNOT-22) and the nasal obstruction symptom evaluation (NOSE) questionnaires and was measured objectively by assessment of nasal patency by peak nasal inspiratory flow (PNIF) at $0,1,3$, and 6 months of treatment in both groups.

Results The average VAS, SNOT-22 and NOSE scores for the septoplasty versus the nonsurgical group before treatment were 6.28 versus $6.0,19.5$ versus 15 , and 14 versus 12, respectively, and at 6 months post-treatment, the scores were 2.9 versus $5.26,10$ versus 12 , and 8 versus $10(p=0.001)$, respectively. The average PNIF scores at 0 and 6 months were $60 / 50 \mathrm{l} / \mathrm{min}$ and $70 / 60 \mathrm{l} / \mathrm{min}$, respectively, in the septoplasty group ( $p=0.001)$; the scores at 0 and 6 months in the nonsurgical management group were $60 / 60 \mathrm{l} / \mathrm{min}$ and $70 / 70 \mathrm{l} / \mathrm{min}$, respectively $(p=0.001)$.

Conclusion Surgical correction of DNS by septoplasty improves nasal obstruction better than nonsurgical management at 6 months postsurgery. received

January 2, 2021

accepted

March 5, 2021

published online

August 23, 2021
DOI https://doi.org/ $10.1055 / \mathrm{s}-0041-1730993$. ISSN 1809-9777.

\footnotetext{
(c) 2021. Fundação Otorrinolaringologia. All rights reserved.

This is an open access article published by Thieme under the terms of the Creative Commons Attribution-NonDerivative-NonCommercial-License, permitting copying and reproduction so long as the original work is given appropriate credit. Contents may not be used for commercial purposes, or adapted, remixed, transformed or built upon. (https://creativecommons.org/ licenses/by-nc-nd/4.0/) Thieme Revinter Publicações Ltda., Rua do Matoso 170, Rio de Janeiro, RJ, CEP 20270-135, Brazil
} 


\section{Introduction}

Deviated nasal septum (DNS) is a widespread clinical condition that affects up to $80 \%$ of the population, as shown in various studies. ${ }^{1}$ It is characterized by displacement of the nasal septum, which normally divides the nasal cavity into right and left nasal passages. Although it is asymptomatic in the majority of patients, the most common and troublesome symptom of DNS is nasal obstruction.

Surgical correction of DNS by septoplasty is one of the most common otorhinolaryngology surgeries in adults. ${ }^{2}$ In the current era, the major indication for septoplasty is nasal obstruction and other associated symptoms of DNS. Although septoplasty is a commonly performed surgery, its effectiveness in relieving nasal obstruction in adults with DNS has not been proven and remains indecisive. Scientific evidence from the literature on the benefits of septoplasty are not well-described. ${ }^{3}$

Many studies have revealed that septoplasty improves health-related quality of life significantly in the postoperative period. ${ }^{4}$ The risk of bias is high, since all available evidence in the literature are based on studies that are only observational in nature, and randomized clinical trials are lacking. The beneficial effects could also be explained by additional factors like the course of the disease or additional interventions such as turbinate reduction or conchoplasty performed in these patients. The biases mentioned above make the advocated benefits of septoplasty questionable and possibly exaggerated.

The present study involves the measurement of both objective (nasal patency) and subjective (quality of life measures) outcome measures for the evaluation of the efficacy of septoplasty, and it is compared with medical management for ameliorating nasal obstruction in patients with DNS. The lack of evidence of the effectiveness of septoplasty explains the need for the present randomized clinical trial.

The aim of the present study was to assess and compare the efficacy of septoplasty with nonsurgical management in improving nasal obstruction in patients with DNS by both subjective and objective measures. The subjective assessment was done by the visual analogue scale (VAS), the nasal obstruction symptom evaluation (NOSE) scale and the sinonasal outcome test-22 (SNOT-22) scores, and the objective assessment was done by peak nasal inspiratory flow (PNIF). ${ }^{5}$

\section{Materials and Methods}

\section{Study Design}

The present study was a randomized clinical trial conducted during the period from February 2017 to December 2018. Informed consent was taken from all the patients who participated in the study. Approval from the Institute Research Council and Ethics Committee (JIP/IEC/2016/1061) was obtained. All provisions of the Declaration of Helsinki were followed. Patients $>18$ years old with nasal obstruction due to DNS were included. Patients with prior septal surgeries, septoplasty done for indications other than DNS, and those with a strong preference to surgery were excluded from the study. With a $5 \%$ level of significance and $90 \%$ power, the sample size was calculated to be 70 in each group for an expected dropout rate of $20 \%$.

Once the diagnosis of DNS was made based on the history of nasal obstruction, clinically by anterior rhinoscopy, and confirmed by diagnostic nasal endoscopy, the patients were randomized into either the septoplasty or the nonsurgical management group by the opaque envelope method.

Nasal patency was assessed at the time of enrollment into the study and at intervals of 1,3 , and 6 months after treatment, subjectively by VAS, SNOT-22, and NOSE score, and objectively by PNIF measurement in both groups.

The VAS scale ranges from 0 to 10 ; with 0 signifying the least severe and 10 the most severe nasal obstruction. In SNOT-22, problems are rated over the past 2 weeks, and each symptom is rated based on its severity. In the NOSE scale, 5 symptoms are considered, and severity is graded from 0 to 4 , with 0 being 'not a problem' and 4 being 'severe problem'. The answers were added and multiplied by 5 to base the scale out of a possible score of 100 points for analysis.

Peak nasal inspiratory flow measures inspiratory flow through the nasal passage. The patients were asked to exhale fully, hold the flow meter horizontally, were ensured that the facemask formed an airtight seal around the nose and inhaled forcibly through the nose. The procedure was done in one nostril at a time by blocking the other. The peak nasal inspiratory maneuver should be a short, sharp, inspiratory action of a duration of $\sim 1$ second ( - Fig. 1 ). The peak nasal inspiratory test was repeated three times, and the highest result was taken into account. The mask was disinfected between patients to avoid cross-infection.

The patients of the septoplasty group were put under sedation, and the procedure was performed under local anesthesia using aseptic precautions. A hemi-transfixion incision was made on the caudal end of the septum and extending from the floor of the vestibule to the dorsum of the columella. Following the incision, mucoperichondrial flaps were elevated from the quadrilateral cartilage until the bony

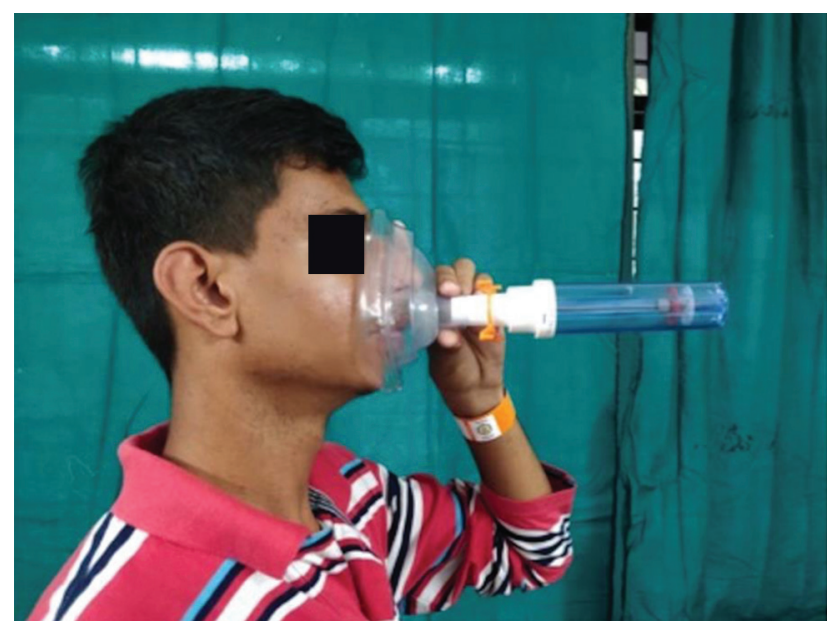

Fig. 1 Patient performing peak nasal inspiratory flow (PNIF) assessment using a PNIF meter. 
Table 1 Comparison of parameters from baseline to 6 months in the septoplasty group

\begin{tabular}{|l|l|l|l|l|l|l|}
\hline \multirow{2}{*}{ S. No. } & Parameter & \multicolumn{2}{|l|}{ Septoplasty group } & \multirow{2}{*}{-value } \\
\cline { 3 - 6 } & & $\mathbf{0}$ month & $\mathbf{1}$ month & $\mathbf{3}$ months & 6 months & \\
\hline 1. & $\begin{array}{l}\text { VAS score } \\
\text { Mean (SD) }\end{array}$ & $6.28(1.4)$ & $4.42(1.6)$ & $3.38(1.2)$ & $2.9(1)$ & 0.001 \\
\hline 2. & $\begin{array}{l}\text { SNOT-22 } \\
\text { Median (IQ range) }\end{array}$ & $19.5(12-24.5)$ & $16(10-20)$ & $12(10-18.7)$ & $10(8-16)$ & 0.001 \\
\hline 3. & $\begin{array}{l}\text { NOSE } \\
\text { Median (IQ range) }\end{array}$ & $70(50-80)$ & $50(50-60)$ & $50(40-58.8)$ & $40(30-50)$ & 0.001 \\
\hline 4. & $\begin{array}{l}\text { PNIF R (IQ range) } \\
\text { Median } \\
\text { L/min }\end{array}$ & $60(40-70)$ & $60(50-75)$ & $60(52.5-80)$ & $70(60-80)$ & 0.001 \\
\hline 5. & $\begin{array}{l}\text { PNIF L } \\
\text { Median (IQ range) } \\
\text { L/min }\end{array}$ & $50(40-70)$ & $60(50-70)$ & $60(50-80)$ & $60(50-80)$ & 0.001 \\
\hline
\end{tabular}

Abbreviations: S. No., Serial number; IQ range, Interquartile range; NOSE, nasal obstruction symptom evaluation; PNIF L, peak nasal inspiratory flow on the left side; PNIF R, peak nasal inspiratory flow on the right side; SD, Standard Deviation; SNOT-22, Sino-nasal outcome test 22; VAS, visual analogue scale.

*Friedman test - nonparametric repeated measures.

cartilaginous junction using a Freer elevator, and an anterior and inferior tunnel were created connecting them. The cartilaginous incision was made anteriorly, and flap elevation and exposure was performed on the contralateral side. The inferior strip of cartilage was removed along the maxillary crest, and at least $1 \mathrm{~cm}$ of the caudal end of the septum was preserved to maintain support of the nasal tip.

Deviated portions of septum were removed, preserving nondeviated parts and a dorsal and a caudal strut to maintain support of the dorsum. Bilateral nasal cavities were packed with merocel or with an antibiotic-antiseptic coated pack to achieve hemostasis. The patients were kept reclined on a couch with $30^{\circ}$ of head end elevation to reduce venous congestion in the septum and reduce bleeding. The pack was removed within 48 hours, and the patients were discharged on a weeklong course of antibiotics and analgesics.

The nonsurgical management group underwent subjective as well as objective assessments of nasal patency as soon as the diagnosis was established and were started on nonsurgical measures like topical nasal decongestants ( $1 \%$ ephedrine drops) for 1 week during each follow-up visit and topical nasal corticosteroid sprays $(50 \mathrm{mcg}$ of fluticasone nasal spray - 1 spray in each nostril administered twice daily up to a total dose of $200 \mathrm{mcg} / \mathrm{day}$ for 6 months). Patients in both groups were followed up at 1, 3, and 6 months from initiation of the the treatment with the same assessment repeated each time.

\section{Results}

The baseline characteristics, including the symptom scores and PNIF values, were comparable between the septoplasty and the nonsurgical management groups in our study. On studying the various parameters from baseline to 6 months in the septoplasty group, there was a significant improvement in symptom scores as well as in PNIF values $(p<0.001)$ ( - Table 1 ). The improvement in symptom scores and in PNIF values was also significant in the nonsurgical management group over 6 months (-Table $\mathbf{2}$ ).

On comparing the septoplasty and the nonsurgical management groups for improvement in subjective and objective measures from baseline to 1 month, there was a statistically significant difference in NOSE scores $(p=0.01)$ and in PNIF left side scores $(p=0.018)$. There was no significant difference in VAS scores $(p=0.679)$, SNOT-22 scores $(p=0.389)$, and PNIF right side values $(p=0.059)$ ( - Table 3 ). On comparing the improvement in symptom scores from baseline to 3 months in both groups, there was a significantly higher improvement in the septoplasty group when compared with the nonsurgical management group. The $p$-value for VAS, SNOT-22 and NOSE scores were 0.001, 0.021, and 0.035, respectively. There was also a significantly higher improvement in the septoplasty group in the objective assessment as measured by PNIF values from both the right $(p=0.003)$ and left side $(p=0.001)$ ( - Table 4$)$. At 6 months, there was a statistically significant difference in improvement in all the symptom scores and in PNIF values between the groups (-Table 5).

\section{Discussion}

A total of 140 patients were recruited in the present study. The patients were randomized into a septoplasty group $(n=70)$ and a nonsurgical management group $(n=70)$. The efficacy of each arm with respect to treatment was assessed at different timepoints, namely, baseline ( 0 month) and at the 1-, 3-, and 6-month post-treatment follow-up.

Out of the 140 patients with nasal obstruction due to DNS, $73(52 \%)$ were males and 67 (48\%) were females. In our study, the ratio between males and females affected by DNS was $1.1: 1$, which is similar to the findings seen in the study by Sriprakash. ${ }^{6}$ In the studies by Moorthy et al. and by Sam et al., the ratio between males and females affected by DNS was $2: 1 .^{7,8}$ Sam et al. mentioned the increased occurrence of 
Table 2 Comparison of parameters from baseline to 6 months in the nonsurgical management group

\begin{tabular}{|l|l|l|l|l|l|l|}
\hline \multirow{2}{*}{ S. No. } & Parameter & \multicolumn{2}{l|}{ Nonsurgical management group } & \multicolumn{2}{l|}{-value $^{*}$} \\
\cline { 3 - 7 } & & $\mathbf{0}$ month & $\mathbf{1}$ month & $\mathbf{3}$ months & $\mathbf{6}$ months \\
\hline 1. & $\begin{array}{l}\text { VAS score } \\
\text { Mean (SD) }\end{array}$ & $6.0(1.5)$ & $4.37(1.6)$ & $4.33(1.6)$ & $5.26(2.3)$ & 0.001 \\
\hline 2. & $\begin{array}{l}\text { SNOT-22 } \\
\text { Median (IQ range) }\end{array}$ & $15(10-22)$ & $12(10-20)$ & $12(10-20)$ & $12(8-20)$ & 0.001 \\
\hline 3. & $\begin{array}{l}\text { NOSE } \\
\text { Median (IQ range) }\end{array}$ & $60(50-80)$ & $50(40-70)$ & $50(25-62.5)$ & $50(30-70)$ & 0.001 \\
\hline 4. & $\begin{array}{l}\text { PNIF R } \\
\text { Median (IQ range) } \\
\text { L/min }\end{array}$ & $60(50-80)$ & $60(50-80)$ & $60(55-85)$ & $70(60-90)$ & 0.001 \\
\hline 5. & $\begin{array}{l}\text { PNIF L } \\
\text { Median (IQ range) } \\
\text { L/min }\end{array}$ & $60(40-72.5)$ & $60(50-85)$ & $70(50-90)$ & $70(50-90)$ & 0.001 \\
\end{tabular}

Abbreviations: S. No., Serial number; IQ range, Interquartile range; NOSE, nasal obstruction symptom evaluation; PNIF L, peak nasal inspiratory flow on the left side; PNIF R, peak nasal inspiratory flow on the right side; SD, Standard Deviation; SNOT-22, Sino-nasal outcome test 22; VAS, visual analogue scale. ${ }^{*}$ Friedman test - nonparametric repeated measures.

Table 3 Comparison of efficacy of treatment groups at 1 month

\begin{tabular}{|c|c|c|c|c|c|c|}
\hline \multirow[t]{2}{*}{ S.No. } & \multirow[t]{2}{*}{ Parameter } & \multicolumn{2}{|c|}{ Septoplasty group } & \multicolumn{2}{|c|}{$\begin{array}{l}\text { Nonsurgical management } \\
\text { group }\end{array}$} & \multirow[t]{2}{*}{ p-value ${ }^{*}$} \\
\hline & & 0 month & 1 month & 0 month & 1 month & \\
\hline 1. & $\begin{array}{l}\text { VAS score } \\
\text { Mean (SD) }\end{array}$ & $6.28(1.4)$ & $4.42(1.6)$ & $6.0(1.5)$ & $4.37(1.6)$ & 0.679 \\
\hline 2. & $\begin{array}{l}\text { SNOT-22 } \\
\text { Median } \\
\text { (IQ range) }\end{array}$ & $19.5(12-24.5)$ & $16(10-20)$ & $15(10-22)$ & $12(10-20)$ & 0.389 \\
\hline 3. & $\begin{array}{l}\text { NOSE } \\
\text { Median } \\
\text { (IQ range) }\end{array}$ & $70(50-80)$ & $50(50-60)$ & $60(50-80)$ & $50(40-70)$ & 0.010 \\
\hline 4. & $\begin{array}{l}\text { PNIF R } \\
\text { Median } \\
\text { (IQ range) }\end{array}$ & $60(40-70)$ & $60(50-75)$ & $60(50-80)$ & $60(50-80)$ & 0.059 \\
\hline 5. & $\begin{array}{l}\text { PNIF L } \\
\text { Median } \\
\text { (IQ range) }\end{array}$ & $50(40-70)$ & $60(50-70)$ & $60(40-72.5)$ & $60(50-85)$ & 0.018 \\
\hline
\end{tabular}

Abbreviations: S. No., Serial number; IQ range, Interquartile range; NOSE, nasal obstruction symptom evaluation; PNIF L, peak nasal inspiratory flow on the left side; PNIF R, peak nasal inspiratory flow on the right side; SD, Standard Deviation; SNOT-22, Sino-nasal outcome test 22; VAS, visual analogue scale.

*Mann-Whitney test.

trauma among males as one of the reasons for the male preponderance in DNS with trauma being a common etiology for DNS. ${ }^{8}$

The ratio of DNS on the right side to DNS on the left side in our study was $1: 1$. In the study by Moorthy et al., DNS was more common on the left side (1.47:1). ${ }^{7}$ A preponderance of left-sided DNS was also observed in a large Korean series by Min et al. In their study, $56 \%$ of the patients had DNS on the left side and $39 \%$ had DNS on the right. The remaining $5 \%$ had S-shaped deformity. ${ }^{9}$

The laterality of DNS could be affected by fetal positions in utero. A right-sided DNS occurs in the left occipitoanterior position, and vice-versa. In the study by Mogarnad et al., right-sided deviations were more common, with a right side to left side ratio of $1.3: 1{ }^{10}$ Serifoglu et al. also found a predominance of right-sided nasal septal deviations in their study, with 107 patients presenting with DNS to the right side and 96 patients presenting with DNS to the left. ${ }^{11}$ This shows that there is no definite pattern in the laterality of DNS, since its cause is multifactorial.

The age range of patients with DNS in our study was between 18 and 55 years old. The average age of all the patients included in our study was 31 years old. In the study by Sam et al., the average age of the patients with DNS was 34.7 years old, and in the study by Ozkul et al., the average age was 32.31 years old, which were in line with our 
Table 4 Comparison of efficacy of treatment groups at 3 months

\begin{tabular}{|l|l|l|l|l|l|l|}
\hline \multirow{2}{*}{ S.No. } & Parameter & \multicolumn{2}{l|}{ Septoplasty group } & \multicolumn{2}{l|}{ Nonsurgical management group } & \multicolumn{2}{l|}{$p$-value* } \\
\cline { 3 - 7 } & & $\mathbf{0}$ month & 3 months & 0 month & 3 months \\
\hline 1. & $\begin{array}{l}\text { VAS score } \\
\text { Mean (SD) }\end{array}$ & $6.28(1.4)$ & $3.38(1.2)$ & $6.0(1.5)$ & $4.33(1.6)$ & 0.001 \\
\hline 2. & $\begin{array}{l}\text { SNOT-22 } \\
\text { Median (IQ range) }\end{array}$ & $19.5(12-24.5)$ & $12(10-18.7)$ & $15(10-22)$ & $12(10-20)$ & 0.021 \\
\hline 3. & $\begin{array}{l}\text { NOSE } \\
\text { Median (IQ range) }\end{array}$ & $70(50-80)$ & $50(40-58.8)$ & $60(50-80)$ & $50(25-62.5)$ & 0.035 \\
\hline 4. & $\begin{array}{l}\text { PNIF R } \\
\text { Median (IQ range) } \\
\text { L/min }\end{array}$ & $60(40-70)$ & $60(52.5-80)$ & $60(50-80)$ & $60(55-85)$ & 0.003 \\
\hline 5. & $\begin{array}{l}\text { PNIF L } \\
\text { Median (IQ range) } \\
\text { L/min }\end{array}$ & $50(40-70)$ & $60(50-80)$ & $60(40-72.5)$ & $70(50-90)$ & 0.001 \\
\hline
\end{tabular}

Abbreviations: S. No., Serial number; IQ range, Interquartile range; NOSE, nasal obstruction symptom evaluation; PNIF L, peak nasal inspiratory flow on the left side; PNIF R, peak nasal inspiratory flow on the right side; SD, Standard Deviation; SNOT-22, Sino-nasal outcome test 22; VAS, visual analogue scale.

*Mann-Whitney test.

Table 5 Comparison of efficacy of treatment groups at 6 months

\begin{tabular}{|l|l|l|l|l|l|l|}
\hline \multirow{2}{*}{ S.No. } & Parameter & \multicolumn{2}{l|}{ Septoplasty group } & \multicolumn{2}{l|}{$\begin{array}{l}\text { Nonsurgical management } \\
\text { group }\end{array}$} \\
\cline { 3 - 6 } & & 0 month & 6 months & 0 month & 6 months \\
\hline 1. & $\begin{array}{l}\text { VAS score } \\
\text { Mean (SD) }\end{array}$ & $6.28(1.4)$ & $2.9(1)$ & $6.0(1.5)$ & $5.26(2.3)$ & 0.001 \\
\hline 2. & $\begin{array}{l}\text { SNOT-22 } \\
\text { Median (IQ range) }\end{array}$ & $19.5(12-24.5)$ & $10(8-16)$ & $15(10-22)$ & $12(8-20)$ & 0.002 \\
\hline 3. & $\begin{array}{l}\text { NOSE } \\
\text { Median (IQ range) }\end{array}$ & $70(50-80)$ & $40(30-50)$ & $60(50-80)$ & $50(30-70)$ & 0.006 \\
\hline 4. & $\begin{array}{l}\text { PNIF R } \\
\text { Median (IQ range) } \\
\text { L/min }\end{array}$ & $60(40-70)$ & $70(60-80)$ & $60(50-80)$ & $70(60-90)$ & 0.001 \\
\hline 5. & $\begin{array}{l}\text { PNIF L } \\
\text { Median (IQ range) } \\
\text { L/min }\end{array}$ & $50(40-70)$ & $60(50-80)$ & $60(40-72.5)$ & $70(50-90)$ & 0.001 \\
\hline
\end{tabular}

Abbreviations: S. No., Serial number; IQ range, Interquartile range; NOSE, nasal obstruction symptom evaluation; PNIF L, peak nasal inspiratory flow on the left side; PNIF R, peak nasal inspiratory flow on the right side; SD, Standard Deviation; SNOT-22, Sino-nasal outcome test 22; VAS, visual analogue scale. *Mann-Whitney test.

study. ${ }^{8,12}$ Possibly, the reason for this can be that patients with DNS usually present in their $3^{\text {rd }}$ decade of life with symptoms of nasal obstruction.

At the end of 6 months, 10 patients were lost to follow-up in the septoplasty group, and 13 were lost to follow-up in the nonsurgical management group. The sample size of 70 patients in each group in our study was calculated with an anticipated dropout rate of $20 \%$. The number of patients who completed the 6 months of follow-up required for the present study was sufficient for analysis.

In the study by Stewart et al., the follow-up rate after septoplasty was of $81 \%$ after 3 months and of $65 \%$ after 6 months. ${ }^{13}$ The follow-up rates were better in our study. Patients who underwent surgical intervention were more inclined to comply with the follow-up for the treatment than the patients in the nonsurgical management group.
The baseline characteristics such as age, gender as well as the questionnaire scores and PNIF values were comparable between the two groups in our study.

Although there was a difference in the baseline SNOT-22 scores between the septoplasty and nonsurgical management groups (19.5 versus 15$)$, this difference was not statistically significant $(p=0.095)$. The mean baseline SNOT-22 score in a study by Hytönen et al. was $21.52 .^{14}$ The mean SNOT-22 score in our study on 140 patients was 18.5 . The mean scores before the treatment was initiated were similar in both studies.

The normal PNIF value in healthy individuals without DNS is between 130 and $140 \mathrm{~L} / \mathrm{min}^{12,15,16}$ In our study, the median preoperative PNIF was 60/50 L/min, and the median postoperative score at 6 months was $70 / 60 \mathrm{~L} / \mathrm{min}$. This could possibly be due to blocking of one nostril and measuring PNIF on the other side leading to decreased inspiratory effort. 
In the septoplasty group, in the comparison of parameters from baseline to 6 months, there was a significant improvement in the VAS, SNOT-22, NOSE and PNIF scores over a period of 6 months $(p=0.001)$.

The nonsurgical management group also showed a significant improvement in parameters from baseline over a period of 6 months $(p=0.001)$.

Comparing the scores of both groups from baseline to 1 month, there was no significant difference in their efficacy $(p>0.05)$. This can be explained by the fact that most patients in the septoplasty group had postoperative edema and crusting in the nasal mucosa as a result of the surgical intervention. ${ }^{17}$ This can be managed by daily regular saline nasal irrigation at home and diagnostic nasal endoscopy with suction clearance in their postoperative visit at the hospital. Nasal decongestants can be added to reduce postoperative edema. Nasal decongestants improve sinus ventilation and drainage due to their vasoconstrictor property, causing shrinkage of the turbinates and, therefore, relieving the obstruction of the osteomeatal complex. $^{18}$

However, comparing the improvement in scores between both groups from baseline to 3 as well as 6 months, there was a significant difference in symptom scores as well as in PNIF values, with septoplasty showing better efficacy in alleviating nasal obstruction than nonsurgical management as measured by their $\mathrm{p}$-value $(p<0.05)$.

In the study by Stewart et al., the mean NOSE scores improved from 67.5 to 26.6 from baseline to 6 months among patients who underwent surgery for DNS. ${ }^{13}$ The median NOSE scores in the septoplasty group in our study were 70 at baseline and 40 at 6 months.

Our results are similar to those of a study by Ozkul et al., in which the mean preoperative and postoperative PNIF values were $102 \mathrm{~L} / \mathrm{min}$ and $139 \mathrm{~L} / \mathrm{min}$, respectively, which showed an objective significant improvement in nasal obstruction by the septoplasty technique. ${ }^{12}$

A meta-analysis involving only 3 prospective controlled trials was performed by Singh et al., in which the authors demonstrated a reduction in the resistance of nasal airway following septoplasty $(p=0.018){ }^{19}$

Moore et al., in a systematic review, concluded that septoplasty improved nasal patency as reflected by objective measurements and, thus, has beneficial effects on the patients undergoing septal surgery. ${ }^{20}$

Hsu et al., in their retrospective cohort study, followed-up patients for 1 year before and after septoplasty with VAS, NOSE score and active anterior rhinomanometry. The patients showed a significant symptom improvement over the period of 1 year. $^{21}$

Teixeira et al. evaluated the usefulness of PNIF in patients with nasal obstruction for objective assessment and found a positive correlation of PNIF with VAS scores. ${ }^{22}$ Our study is the only prospective study to assess the improvement with treatment in DNS patients by all three subjective assessment scores (VAS, SNOT-22 and NOSE). An added strength to our study is the usage of an objective measurement tool in the form of PNIF values.
Our study was a well-planned prospective randomized clinical trial performed with a good sample size of 70 patients in each group. All patients in the surgical treatment group in our study underwent only septoplasty as the surgical technique. Most studies that evaluated subjective and objective parameters on DNS patients with nasal obstruction were observational or retrospective in nature or involved different types of surgical procedures and were performed with much smaller sample sizes. ${ }^{23-25}$

In septoplasty, DNS is straightened, causing a widening of the nasal passages. This results in improved ventilation and inspiratory effort in patients with nasal obstruction. It also improves mucociliary clearance and, therefore, improves nasal breathing. ${ }^{26,27}$ It also alleviates other associated symptoms of DNS such as headache, epistaxis, snoring, and sleep disturbances, therefore improving quality of life. ${ }^{14}$ This was evident from the improvement in subjective assessment scores in our study.

\section{Limitations of the Study}

The severity of nasal obstruction based on degrees of septal deviation was not measured. The evaluation of long-term complications in both treatment groups was not studied in detail. The cost-efficacy of the treatment groups was not studied in the present study. Septoplasty surgeries were not performed by the same surgeon in our study. The types of septal deviation and their specific treatment outcomes were not studied.

\section{Conclusion}

Septoplasty is more efficacious than medical management in the long run in alleviating nasal blockade in DNS patients. Nonsurgical management is effective in a short-term basis (when used for a period of 1 month) and fails to show significant improvement thereafter. Hence, it can be considered in patients while awaiting surgery. Patients with mild to moderate DNS can be considered for a trial of nonsurgical management and, if it fails to show improvement beyond 1 month, they should be submitted to septoplasty.

Note

The present paper was presented at the $14^{\text {th }}$ Asia Oceana ORL-HNS Congress and AOICON 2019, held at Hyderabad, India, from 9 to 13 January 2019.

\section{Source of Funding}

None to declare.

Conflict of Interests

The authors have no conflict of interests to declare.

\section{References}

1 Roblin DG, Eccles R. What, if any, is the value of septal surgery? Clin Otolaryngol Allied Sci 2002;27(02):77-80

2 van Egmond MMHT, Rovers MM, Tillema AHJ, van Neerbeek N. Septoplasty for nasal obstruction due to a deviated nasal septum in adults: a systematic review. Rhinology 2018;56(03):195-208 
3 Alotaibi A, Almutlaq BA, Ahmed HG. Time for Recovery of Symptoms after Septoplasty. Afr J Med Med Sci 2017;7:350-355

4 Bugten V, Nilsen AH, Thorstensen WM, Moxness MH, Amundsen MF, Nordgård S. Quality of life and symptoms before and after nasal septoplasty compared with healthy individuals. BMC Ear Nose Throat Disord 2016;16(01):1-7

5 Malm L. Measurement of nasal patency. Allergy 1997;52(40, Suppl)19-23

6 Sriprakash V. Prevalence and clinical features of nasal septum deviation: a study in an urban centre. Int J Otorhinolaryngol Head Neck Surg 2017;3(04):842-844

7 Moorthy PNS, Kolloju S, Madhira S, Jowkar AB. Clinical Study on Deviated Nasal Septum and Its Associated Pathology. Int J Otolaryngol Head Neck Surg 2014;3:75-81

8 Sam A, Deshmukh PT, Patil C, Jain S, Patil R. Nasal septal deviation and external nasal deformity: a correlative study of 100 cases. Indian J Otolaryngol Head Neck Surg 2012;64(04):312-318

9 Min YG, Jung HW, Kim CS. Prevalence study of nasal septal deformities in Korea: results of a nation-wide survey. Rhinology 1995;33(02):61-65

10 Mogarnad M, Mohta V. A Study on Clinical Profile of Deviated Nasal Septum and to determine the Efficacy of the Surgery. Headache 2015;51:85

11 Serifoglu I, Oz II, Damar M, Buyukuysal MC, Tosun A, Tokgöz Ö Relationship between the degree and direction of nasal septum deviation and nasal bone morphology. Head Face Med 2017;13 (01):1-6

12 Ozkul HM, Balikci HH, Gurdal MM, et al. Normal range of peak nasal inspiratory flow and its role in nasal septal surgery. J Craniofac Surg 2013;24(03):900-902

13 Stewart MG, Smith TL, Weaver EM, et al. Outcomes after nasal septoplasty: results from the Nasal Obstruction Septoplasty Effectiveness (NOSE) study. Otolaryngol Head Neck Surg 2004; 130(03):283-290

14 Hytönen ML, Lilja M, Mäkitie AA, Sintonen H, Roine RP. Does septoplasty enhance the quality of life in patients? Eur Arch Otorhinolaryngol 2012;269(12):2497-2503

15 Blomgren K, Simola M, Hytönen M, Pitkäranta A. Peak nasal inspiratory and expiratory flow measurements-practical tools in primary care? Rhinology 2003;41(04):206-210
16 Ottaviano G, Scadding GK, Coles S, Lund VJ. Peak nasal inspiratory flow; normal range in adult population. Rhinology 2006;44(01): 32-35

17 Dąbrowska-Bień J, Skarżyński PH, Gwizdalska I, Łazęcka K, Skarżyński H. Complications in septoplasty based on a large group of 5639 patients. Eur Arch Otorhinolaryngol 2018;275(07):1789-1794

18 Stringer SP, Mancuso AA, Avino AJ. Effect of a topical vasoconstrictor on computed tomography of paranasal sinus disease. Laryngoscope 1993;103(1 Pt 1):6-9

19 Singh A, Patel N, Kenyon G, Donaldson G. Is there objective evidence that septal surgery improves nasal airflow? J Laryngol Otol 2006;120(11):916-920

20 Moore M, Eccles R. Objective evidence for the efficacy of surgical management of the deviated septum as a treatment for chronic nasal obstruction: a systematic review. Clin Otolaryngol 2011;36 (02):106-113

21 Hsu HC, Tan CD, Chang CW, et al. Evaluation of nasal patency by visual analogue scale/nasal obstruction symptom evaluation questionnaires and anterior active rhinomanometry after septoplasty: a retrospective one-year follow-up cohort study. Clin Otolaryngol 2017;42(01):53-59

22 Teixeira RUF, Zappelini CEM, Alves FS, da Costa EA. Peak nasal inspiratory flow evaluation as an objective method of measuring nasal airflow. Rev Bras Otorrinolaringol (Engl Ed) 2011;77(04): 473-480

23 Murrell GL. Correlation between subjective and objective results in nasal surgery. Aesthet Surg J 2014;34(02):249-257

24 Umihanic S, Brkic F, Osmic M, et al. The discrepancy between subjective and objective findings after septoplasty. Med Arh 2016;70(05):336-338

25 Eren SB, Tugrul S, Dogan R, Ozucer B, Ozturan O. Objective and subjective evaluation of operation success in patients with nasal septal deviation based on septum type. Am J Rhinol Allergy 2014; 28(04):e158-e162

26 Polat C, Dostbil Z. Evaluation of the nasal mucociliary transport rate by rhinoscintigraphy before and after surgery in patients with deviated nasal septum. Eur Arch Otorhinolaryngol 2010;267 (04):529-535

27 Dobratz EJ, Park SS. Septoplasty pearls. Otolaryngol Clin North Am 2009;42(03):527-537 